\title{
Exploring Relationships Between Learners' Internet Self-efficacy, Online Self-Regulation, and Interaction during Online Learning amid COVID-19 in Vietnam
}

\author{
Thach Pham ${ }^{1 *}$, Phuong Lai ${ }^{2}$, Vinh Nguyen ${ }^{3}$
}

\author{
${ }^{1}$ Board of Trustees, Hanoi University \\ ${ }^{2}$ Faculty of Management and Tourism, Hanoi University \\ ${ }^{3}$ English Department, Hanoi University \\ *Corresponding author.Email: thachpn@hanu.edu.vn
}

\begin{abstract}
Internet self-efficacy and self-regulation/autonomy have proven to play essential roles in online learning, especially during the compulsory closure of educational institutions due to Covid-19 all over the world. This study was conducted in an attempt to explore the inter-relationships among three constructs: Internet self-efficacy, online self-regulation, and interaction during the emergency online learning amid Covid-19 in Vietnam. A partial least squares structural equation modeling (PLS-SEM) was used to mine the data collected from over two thousand undergraduate students at a Vietnamese university. Research results indicated that Internet self-efficacy was a significant predictor of learner autonomy directly and indirectly through learner-content, learner-instructor, and learner-learner interactions. The study findings also revealed significant differences between learners of language and non-language majors, between those with a prior online learning experience and those without in the relationships among the constructs mentioned above. However, gender did not have any impact on the relationships. The study findings provide new insights and useful implications for teachers and students in promoting learners' Internet self-efficacy, self-regulation, and online interaction in the context of oriental cultures where students tend to rely on their teachers in both traditional and online learning.
\end{abstract}

Keywords: Self-efficacy, Self-regulation, Online interaction, PLS-SEM, COVID-19, Vietnam.

\section{INTRODUCTION}

Over the past two years, countries worldwide faced unprecedented outbreaks of Coronavirus infectious disease (called COVID-19). The disease spread continuously with new variants causing numerous hardships for governments and people, including students who had to study online for most of the 2020 and 2021 school years. Indeed, due to the recurring outbreaks, all countries became large-scale experimental sites for online teaching and learning, which was considered not a temporary replacement of the traditional model of educational delivery, but a permanent option in curricula [1], [2]. In higher education contexts, this compulsory online teaching and learning provided opportunities for universities to adapt through making the most use of technological infrastructure and training of staff to excel [3]. However, unlike in the West, universities in the developing world had to rely on free applications like Zoom or Google Meet to deliver lesson content through live online lessons. These make-shift online lessons posed quite a few problems for both teachers and students, many of whom might have never taught or learnt online before [4], [5]. Some of these problems included adapting pedagogical techniques, modifying materials (for teachers), adjusting interaction techniques, enhancing Internet competencies, and fostering self-study skills to suit online learning contexts (for students).

Over the years before the first outbreak of Covid19, the Government of Vietnam and its Ministry of Education and Training (MOET) had issued policies, circulars and developed distance and online courses to students and the public [6], [7]. Distance learning and online learning were implemented through national television channels and other Internet platforms. They covered a wide range of areas, such as languages, 
general knowledge, life skills, and school subjects like mathematics, physics, chemistry, especially before the entrance examination to university in Vietnam (usually in July). However, due to the recurring outbreaks of the pandemic through the years 2020 and 2021, the national government and its provincial educational management authorities had to repeatedly adjust their policies regarding schooling plans. Some of these included the delay or even cancelation of high school completion examination, changing schooling duration, and to a more considerable extent, encouraging digitalization in education [1], [8].

A few research projects were conducted during this time on different aspects of education, such as factors affecting students' online learning intention and satisfaction, teachers' and students' adaptability in the new environments [2], [3], [5]. Nevertheless, there are still gaps in online interaction, learners' Internet selfefficacy, self-regulation, which are some of the critical constructs of online learning [9]. Therefore, the current study aimed to explore the relationships among the three types of interaction in an online learning environment, namely learner-learner (L-L), learnerinstructor $(\mathrm{L}-\mathrm{I})$, learner-content $(\mathrm{L}-\mathrm{C})$, learners' perceived Internet self-efficacy (PIS), and learner selfregulation (SR). What distinguished the current study from those in the literature was that while past studies have examined the influence of interaction, PIS and SR on learning outcomes of satisfaction, this study tried to explore how PIS and online interaction affected learners' SR. Three reasons for this seemingly reversed pattern of influence are presented below.

First, due to Covid-19, all the teachers had to deliver their lessons live without sufficient preparation on how to make the most use of the live conferencing applications (e.g., Zoom) for teaching purposes; how to facilitate online interaction with and among students in either the main screen or breakout rooms. There were also issues concerning modifying the course materials originally designed for conventional teaching [4]. Hence, in the process of live online teaching and learning, both teachers and students had to adapt to the new mode of interaction through more appropriate teaching pedagogy and self-study strategies [5]. This adaptation could have had some impacts on learners' self-regulation.

Second, previous research has indicated that online SR, unlike in a traditional classroom context, is more student-centered, and more effort is required from students and support from instructors [10]. However, in the Vietnamese context, like some other Asian countries such as China, Malaysia, or Korea, teachers tend to believe that their students are passive, which restricts students' engagement in autonomous learning without teachers' guidance [11]. Because of the Covid-19 pandemic, students were forced to study online without sufficient technical preparation and teachers' instructions for proactive online interaction with teachers, peers and course materials. Despite these problems, they had to interact in the live online lessons. Hence, they had to adjust their SR strategies to study in a new learning environment. In other words, new interactional contexts might have influenced their past self-study skills.

Third, technical issues have been one of the main barriers to online learning during the pandemic, as revealed in recent studies [12], [5]. Although the current generation of students was considered digital natives, their competencies in using technology for learning purposes should not be taken for granted. In the context of a developing country like Vietnam, slow Internet connectivity and weak digital competence of a proportion of students might negatively influence interaction [5]. Hence, students had to improve their PIS and SR further to meet the new requirements in online learning.

In short, due to the compulsory live online learning amid Covid-19, the relationships among online interaction, PIS and SR could have been different from the typical online learning situations. The current study investigated these relationships through a partial least squares structural equation modeling (PLS-SEM) analysis.

\section{LITERATURE REVIEW}

\subsection{Self-regulation}

Self-regulation is a close concept to learner autonomy [13]. According to Zimmerman [14, p. 329], self-regulated learners are: "metacognitively, motivationally, and behaviorally active participants in their learning process." Schunk and Zimmerman [15] indicated a direct connection between self-regulation and motivation by arguing that self-regulated learners are proactive in reaching the learning goals and taking control of the learning process because they are intrinsically motivated to do so. Earlier, Zimmerman [14] also argued that self-regulated learners must have high self-efficacy toward the learning task and commitment to learning goals.

The common view from studies about learner autonomy and self-regulation is that both are important for learners to achieve learning goals [15]. Learner autonomy and self-regulation both highlight the activeness of the learner during the learning 
process, especially in setting goals, selecting materials, choosing strategies, monitoring learning, and assessing learning. Also, the two concepts accentuate active engagement, goal-directed behavior, metacognitive skills, and intrinsic motivation of the learner to control their learning. In other words, selfregulation is a manifestation of learner autonomy in which learners take responsibility for all the decisions related to their learning [13].

The relationship between SR and other constructs of online learning has been investigated in a few research projects [16], [17], [9]. Cho and Cho [16] explored the influence of SR in three types of interaction on learner self-efficacy and online course satisfaction. The results revealed that $\mathrm{SR}$ in $\mathrm{L}-\mathrm{C}$ and L-I were strongly related to learners' self-efficacy and satisfaction with the online course; however, SR in LL was not. Cho and Cho [16] considered that SR played an essential role in enhancing the quantity and quality of three types of interaction. Learners take charge in understanding the course content, initiating interaction with instructors, and collaborating with peers to fulfill class activities.

Similarly, Hamdan et al. [17] asserted that higher self-regulation led to higher satisfaction in online learning. In a recent study, Landrum [18] also found that self-regulation was among the strongest positive predictors of satisfaction. Nonetheless, the two studies by Kuo et al. [9] and Eom and Ashill [19] revealed that self-regulation was not a predictor of learner satisfaction in online learning.

\subsection{Internet Self-efficacy}

Bandura [20] and Schunk [21] defined selfefficacy as learner perception of their ability to perform tasks successfully. In their arguments, selfefficacy is integral to self-regulation. It affects the choice of activities and the amount of effort invested by the learner while doing the tasks. Learners with high self-efficacy make more effort than those who are not confident about their ability. Self-efficacy is essential in the learning process because both capabilities and beliefs influence accomplishing a task [20].

Since the extensive research on the concept of selfefficacy conducted by Bandura [20], many studies have examined the effects of ICT and Internet selfefficacy on learning. For example, Rohatgi et al. [22] revealed that self-efficacy in basic ICT skills was positively related to computer and information literacy achievement. In contrast, self-efficacy in advanced ICT skills showed a negative relation. Furthermore,
ICT use and ICT self-efficacy are positively correlated for some of the ICT use purposes. Hatlevik et al. [23] found that ICT self-efficacy was positively associated with ICT literacy. In addition, the level of ICT selfefficacy is affected by learner experience with autonomous learning, technological and socioeconomic background.

Internet self-efficacy depicts learners' confidence in using the computer, LMS and the Internet to seek information and execute Internet-related actions [9]. Research in the literature shows that Internet selfefficacy is positively related to academic performance in virtual learning environments. For example, Tsai and Tsai [24] indicated that higher Internet selfefficacy led to better strategies and academic performance in web-based learning tasks. However, there was inconsistency in the findings of past studies about the influence of Internet self-efficacy on satisfaction. While studies by Thach et al. [4] and Yilmaz [25] indicated a positive correlation between these two variables, the findings of studies by Hamdan et al. [17] and Kuo et al. [9] revealed the opposite. It seems that in both normal and emergency online learning contexts, high Internet self-efficacy does not ensure good learning gains.

\subsection{Online Interaction}

Interaction has consistently been considered an essential element in online learning, together with other constructs such as Internet self-efficacy, selfregulation, online teaching pedagogy, and support from educational institutions [9], [26]. Moore [27], commonly cited in distance education, categorized three critical types of interaction: L-C, L-I, and L-I. Later, Hillman et al. [28] proposed learner-interface as the fourth type of interaction found in web-based learning. However, the first three forms of interaction remain the most widely acknowledged types of interaction as they can be found in both traditional classrooms and virtual learning environments.

These three types of interaction are affected by many factors related to the learners themselves, such as satisfaction [9] or self-efficacy [2]. Learners' interaction with content is how learners exploit the materials embedded in the online course for their study purposes. In the compulsory online learning due to Covid-19, the learners interacted with the course content in live online sessions and the materials uploaded in the institutional learning management system (LMS) or other platforms. The quality or effectiveness of learners' comprehension of the live lectures of reading materials depended on instructors' technical competencies, online pedagogical skills, and 
the materials initially designed for conventional learning [4], [3]. Nevertheless, this issue has not been extensively explored in the literature.

Learners' interaction with an instructor in an online environment depends significantly on the quantity and quality of instructors' facilitation and feedback [19], [2]. In this regard, instructors have to play many roles, including course content designers, learning facilitators [29]. However, during the emergency context, not all the instructors had enough time to prepare and adapt to the new teaching context, including how to foster online interaction with the students in the new environment [4], [30]. This may have had adverse effects on learner-instructor interaction [31].

In addition, there were technical and cultural barriers that could negatively affect learner-instructor interaction. From a technical perspective, slow Internet connection and learners' limited Internet competencies hindered the interaction [31], [2]. Learners from the countryside might have been less advantageous than those living in big cities with good Internet connections. From the cultural aspect, Asian learners view their teachers as respectable authorities and reliable sources of knowledge in their field [11]. Hence, they tend to refrain from arguing or sharing different views about academic matters [32].

Learner-learner interaction could be in a one-toone or one-to-many format. Interaction with peers motivates learners to excel through mutual collaboration and moderation for learning [33]. Due to Covid-19, learners were assigned to collaborate in video conferencing applications breakout rooms (e.g., Zoom). However, there were numerous unanswered questions about the quality of their discussions. For example, the instructors could not monitor the process and quality of all the breakout rooms. Due to the emergency, instructors could have been trained on how to put students in different rooms, but possibly not on how to foster live interaction among the students. In addition, students might not have been familiar with this way of online discussion before and faced numerous problems [31].

In short, quite a few studies have been conducted on the relationship between interaction, Internet selfefficacy, self-regulation and online learning outcomes or satisfaction [25], [19], [17], [9], [3]. Among the independent constructs, learner-content consistently and positively impacted learner satisfaction. On the other hand, the effects of learner-instructor and learner-learner interaction on learning satisfaction have been mixed, especially during online emergency learning [4], [17], [2]. Findings of the influence of
Internet self-efficacy and self-regulation were inconclusive. For example, while most past studies have revealed that self-regulation was not a predictor of online learning satisfaction, studies by Alqurashi [25] and Thach et al. [3] indicated a positive relationship between learning self-efficacy and selfregulation and satisfaction.

The above literature review shows that three constructs: interaction, Internet self-efficacy, and selfregulation, have mostly affected learners' online performance and satisfaction. On the other hand, this study aimed to investigate the possible interrelationships among these three factors in a Vietnam higher education context during the emergency live online learning. More specifically, the study sought to test the following seven hypotheses.

1. H1: $\mathrm{L}-\mathrm{L}$ interaction has a direct positive relationship with learners' SR

2. H2: L-I interaction has a direct positive relationship with learners' SR.

3. H3: L-C interaction has a direct positive relationship with learners' $\mathrm{SR}$

4. H4: PIS is directly related to learners' SR.

5. H5: The relationship between learners' PIS and SR is mediated by $\mathrm{L}-\mathrm{L}$ interaction.

6. H5: The relationship between learners' PIS and SR is mediated by L-I interaction.

7. H5: The relationship between learners' PIS and $\mathrm{SR}$ is mediated by $\mathrm{L}-\mathrm{C}$ interaction.

Based on the literature review, a theoretical framework was proposed to explore the relationships among different types of interaction, learners' perceived Internet self-efficacy, and self-regulation in the current study (Figure 1).

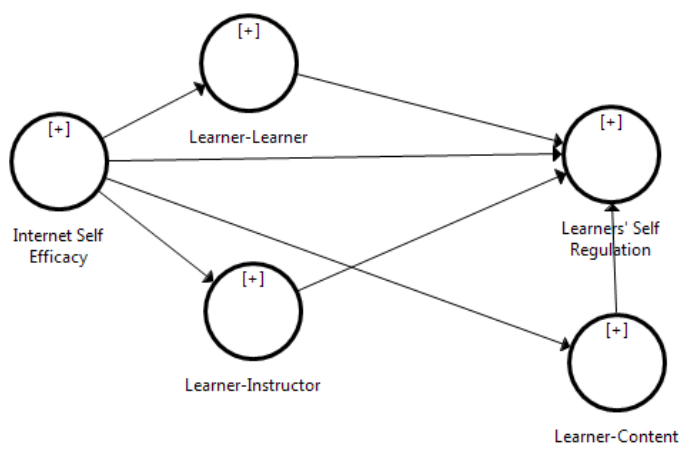

Figure 1 Proposed model. 


\section{MATERIALS AND METHODS}

\subsection{Instrument}

A questionnaire comprising demographic variables and key online learning factors were used as the primary data collection instrument. The questionnaire items were adapted from the previous studies on three types of interaction with the addition of learners' Internet self-efficacy and self-regulation [34], [35], [9]. The most considerable modification was using a 4-point response format with the elimination of 'neutral' instead of 5- or 7-point scales. This modification was based on studies by Lee et al. [36] and Wang et al. [37], suggesting that Asian learners tended to select 'neutral' as a safe choice or avoid potential conflicts.

The questionnaire items were translated into Vietnamese and checked by the researchers who specialized in teaching English. They were then commented on for clarity in a group discussion with Vietnamese nationals and online learning experts, and some modifications were made. For example, some of the items in the online SR section were eliminated (e.g., I find myself pausing regularly to check my comprehension of this online course). This was because all the students had to follow the same pace of the live online lesson. Hence, this question was not contextually appropriate. The questionnaire was then piloted on 81 students who were studying online in different disciplines. While completing the questionnaire, they were also invited to comment on the wording and clarity of the items. Minor changes were further made following their comments. For instance, there was an explanation of the word 'content' to refer to the teachers' live delivery of the PowerPoint slides and the materials sent to the students in advance.

Besides collecting learners' demographic information, the questionnaire consisted of key items that measured learners' online interaction, their PIS and SR. The PIS items were adapted from Eastin and LaRose [38] to measure learners' perceived competencies in starting an application for online learning, browsing the Internet, searching information, sharing materials online, etc. The learners' online SR measurements were adapted from Jansen et al. [39], which measured learners' six competencies in online learning, namely metacognitive skills, time management, environmental structuring, persistence, help-seeking, and self-assessment. Finally, measurement scales for learners' interaction with content, peers and instructors were adapted from Kuo et al. [9]. Sample items were: "Online course materials helped me to understand better the class content," "I got lots of feedback from my classmates," and "I had numerous interactions with the instructor during the class."

\subsection{Participants}

Participants were undergraduate students at a Vietnamese university. They learned foreign languages like English, Chinese, Japanese, and other disciplines such as business administration, information technology, banking and finance through the media of English and French. They stayed at home in the capital city of Hanoi or their hometowns to access online lessons delivered via Zoom or Google Meet applications. They had online lessons for all language practice courses, interpreting and translation (for language majors), and specialized courses (for non-language majors) except for physical education.

Before the launch of live online classes, teachers and students were provided with a half-a-day training session, mainly on how to use technical functions of the applications for setting up a class, recording lessons, uploading materials, and even using social networks for out-of-live sessions. The online content and materials were adapted from conventional lessons to maximize interaction between the instructors and learners and among the learners. Both the teachers and students were requested to use the institutional email accounts for their teaching and learning.

The study was conducted two months after the students switched to online learning due to the first outbreak of Covid-19 in Vietnam. Participants took part in the survey voluntarily and were informed that they could withdraw at any time. Using convenience sampling technique, the survey was administered online to all the students. An electronic link was also sent to the teachers who told their students about the survey to increase response rates. After ten days, 3,036 responses, accounting for $30 \%$ of the university's student population, were obtained. After cleaning the data (eliminating missing and non-valid answers), 2,338 responses were usable for data analysis. Descriptive analysis of respondents is tabulated in Table 1. 
Table 1. Data profile.

\begin{tabular}{|llrr|}
\hline & & Frequency & Percent \\
\hline Year of Study & 1 & 816 & 34.9 \\
& 2 & 704 & 30.1 \\
& 3 & 604 & 25.8 \\
& 4 & 214 & 9.2 \\
& Total & 2338 & 100 \\
\hline Gender & Female & 2119 & 90.6 \\
& Male & 219 & 9.4 \\
& Total & 2338 & 100 \\
\hline Prior Expe rience & No & 1714 & 73.3 \\
& Yes & 624 & 26.7 \\
& Total & 2338 & 100 \\
\hline Major & Non-language Major & 480 & 20.6 \\
& Language Major & 1858 & 79.4 \\
& Total & 2338 & 100 \\
\hline
\end{tabular}

Table 2. Evaluation for the formative measurement model.

\begin{tabular}{|c|c|c|c|c|c|c|c|c|}
\hline \multirow{2}{*}{ Formative Construct } & \multirow{2}{*}{$\begin{array}{l}\text { Formative } \\
\text { Indicator }\end{array}$} & \multicolumn{2}{|c|}{ Outer weights } & \multicolumn{2}{|c|}{ Outer loadings } & \multicolumn{2}{|c|}{ 95\% CI (Outer weights) } & \multirow{2}{*}{ VIF } \\
\hline & & Outer weight & p-value & Outer loading & $\mathrm{p}$-value & LCL & UCL & \\
\hline \multirow[t]{4}{*}{ Learner-Content } & LC5 & 0.387 & 0.000 & 0.816 & 0.000 & 0.304 & 0.463 & 1.609 \\
\hline & LC6 & 0.295 & 0.000 & 0.753 & 0.000 & 0.222 & 0.370 & 1.516 \\
\hline & LC7 & 0.258 & 0.000 & 0.806 & 0.000 & 0.152 & 0.354 & 2.124 \\
\hline & LC8 & 0.320 & 0.000 & 0.791 & 0.000 & 0.224 & 0.419 & 1.961 \\
\hline \multirow[t]{4}{*}{ Learner-Instructor } & LI1 & 0.388 & 0.000 & 0.703 & 0.000 & 0.329 & 0.446 & 1.203 \\
\hline & LI6 & 0.351 & 0.000 & 0.732 & 0.000 & 0.289 & 0.409 & 1.356 \\
\hline & LI7 & 0.279 & 0.000 & 0.688 & 0.000 & 0.218 & 0.338 & 1.335 \\
\hline & LI8 & 0.378 & 0.000 & 0.734 & 0.000 & 0.317 & 0.443 & 1.281 \\
\hline \multirow[t]{5}{*}{ Learner-Learner } & LL2 & 0.261 & 0.000 & 0.701 & 0.000 & 0.174 & 0.346 & 1.858 \\
\hline & LL3 & 0.219 & 0.000 & 0.676 & 0.000 & 0.135 & 0.306 & 1.836 \\
\hline & LL4 & 0.255 & 0.000 & 0.654 & 0.000 & 0.186 & 0.320 & 1.284 \\
\hline & LL5 & 0.326 & 0.000 & 0.730 & 0.000 & 0.249 & 0.406 & 1.499 \\
\hline & LL6 & 0.336 & 0.000 & 0.786 & 0.000 & 0.254 & 0.415 & 1.602 \\
\hline \multirow[t]{12}{*}{ Internet Self Efficacy } & PIS1 & 0.269 & 0.000 & 0.761 & 0.000 & 0.173 & 0.362 & 2.258 \\
\hline & PIS10 & 0.157 & 0.001 & 0.801 & 0.000 & 0.058 & 0.251 & 2.519 \\
\hline & PIS11 & -0.017 & 0.728 & 0.707 & 0.000 & -0.115 & 0.082 & 2.273 \\
\hline & PIS12 & 0.211 & 0.000 & 0.733 & 0.000 & 0.124 & 0.307 & 1.917 \\
\hline & PIS2 & 0.057 & 0.231 & 0.727 & 0.000 & -0.039 & 0.145 & 2.602 \\
\hline & PIS3 & -0.050 & 0.374 & 0.709 & 0.000 & -0.166 & 0.057 & 3.115 \\
\hline & PIS4 & -0.022 & 0.783 & 0.724 & 0.000 & -0.167 & 0.136 & 6.871 \\
\hline & PIS5 & 0.065 & 0.409 & 0.738 & 0.000 & -0.093 & 0.218 & 7.077 \\
\hline & PIS6 & 0.063 & 0.263 & 0.769 & 0.000 & -0.053 & 0.163 & 2.646 \\
\hline & PIS7 & 0.207 & 0.000 & 0.821 & 0.000 & 0.105 & 0.302 & 2.657 \\
\hline & PIS8 & 0.240 & 0.000 & 0.769 & 0.000 & 0.159 & 0.319 & 1.835 \\
\hline & PIS9 & 0.123 & 0.004 & 0.696 & 0.000 & 0.041 & 0.209 & 1.788 \\
\hline \multirow[t]{16}{*}{ Self Regulation } & SR1 & 0.146 & 0.000 & 0.645 & 0.000 & 0.093 & 0.194 & 1.812 \\
\hline & SR 10 & 0.160 & 0.000 & 0.609 & 0.000 & 0.116 & 0.212 & 1.425 \\
\hline & SR11 & 0.198 & 0.000 & 0.657 & 0.000 & 0.144 & 0.252 & 1.485 \\
\hline & SR12 & -0.011 & 0.641 & 0.515 & 0.000 & -0.060 & 0.039 & 1.719 \\
\hline & SR13 & 0.012 & 0.461 & 0.456 & 0.000 & -0.028 & 0.066 & 1.428 \\
\hline & SR14 & 0.067 & 0.005 & 0.567 & 0.000 & 0.021 & 0.116 & 1.472 \\
\hline & SR 15 & 0.200 & 0.000 & 0.648 & 0.000 & 0.140 & 0.238 & 1.557 \\
\hline & SR16 & 0.069 & 0.006 & 0.628 & 0.000 & 0.021 & 0.126 & 1.759 \\
\hline & SR2 & 0.123 & 0.000 & 0.676 & 0.000 & 0.071 & 0.177 & 1.854 \\
\hline & SR3 & 0.045 & 0.087 & 0.653 & 0.000 & -0.006 & 0.102 & 1.874 \\
\hline & SR4 & 0.097 & 0.000 & 0.619 & 0.000 & 0.048 & 0.144 & 1.633 \\
\hline & SR5 & 0.077 & 0.002 & 0.567 & 0.000 & 0.127 & 1.539 & 1.539 \\
\hline & SR6 & 0.109 & 0.000 & 0.617 & 0.000 & 0.156 & 1.518 & 1.518 \\
\hline & SR7 & 0.129 & 0.000 & 0.566 & 0.000 & 0.179 & 1.619 & 1.619 \\
\hline & SR8 & 0.037 & 0.143 & 0.531 & 0.000 & 0.089 & 1.436 & 1.436 \\
\hline & SR9 & 0.136 & 0.000 & 0.664 & 0.000 & 0.184 & 1.642 & 1.642 \\
\hline
\end{tabular}




\subsection{Data Analysis and Model Specification}

The technique of partial least squares (PLS) developed by Herman O. A. Wold [40] was used instead of the covariance-based structural model. The method was built on the foundation that explained variance of the endogenous constructs were to be maximized and error terms minimized [41]. As a result, it is more appropriate in exploratory research [42] and examining causal relations among constructs [41]. Besides, PLS can be carried out without the assumption of normal distribution [41] and is a suitable choice in the presence of convergence issues with formative models [43]. Every calculation in this study was done with the help of SmartPLS 3.3.2 [44].

Partial least squares structural equation modeling (PLS-SEM) has been utilized in earlier studies that explored the relationship between different variables of the technology acceptance model (TAM) in ordinary or emergency online learning contexts [45], [46]. This analysis technique combined ordinary least square regression with principal component analysis to estimate partial model structure. Since the proposed model in the current study was new, PLS-SEM was useful in testing a theoretical framework from an exploratory perspective [41]. In addition, Likert-scale data in this study were neither continuous nor Gaussian in distribution [47]; therefore, using a causal-predictive approach was a suitable technique to provide necessary causal explanations of the variables in the current study [41].

\section{RESULTS}

\subsection{Evaluation of the Measurement Model}

The validity and reliability of the formulated formative measurement model are assessed based on several criteria recommended by Hair et al. [41], namely potential collinearity and indicators' statistical significance and relevance.

As illustrated in Table 2, all variance inflation factor (VIF) values are well below 5, except for PIS4 (6.871) and PIS5 (7.077); therefore, collinearity does not seem to be a critical issue. All items within the three types of interaction constructs were statistically significant at 5\% (two-tailed). All items except PIS2, PIS3, PIS4, PIS5, PIS6 and PIS11 were major contributors within the PIS construct, while SR3, SR8, SR12, and SR13 were perceived as significant contributors for the SR construct. As outer loadings of these indicators are all greater than 0.5 and significant at a $1 \%$ level of significance, these indicators are retained in the formative model despite their insignificant outer weights.

\subsection{Evaluation of the Structural Model}

Table 3. Predictive power and relevance

\begin{tabular}{lcc} 
& $\mathrm{R}^{2}$ Adjusted & $\mathrm{Q}^{2}$ \\
\hline Learner-Content & 0.166 & 0.104 \\
Learner-Instructor & 0.204 & 0.103 \\
Learner-Learner & 0.164 & 0.091 \\
Learners' Self Regulation & 0.544 & 0.192 \\
\hline
\end{tabular}

The coefficient of determination $\left(\mathrm{R}^{2}\right)$ measures the in-sample predictive power of the proposed structural model. As presented in Table 3, the value of $\mathrm{R}^{2}$ for the endogenous construct (learners' SR) is $54.4 \%$, indicating a moderate predictive accuracy level. Table 3 also demonstrates quite satisfactory $\mathrm{R}^{2}$ level with the coefficients of determination for the learner-content interaction (0.166, weak), learner-instructor interaction (0.204, weak), and learner-learner interaction $(0.164$, weak).

The predictive relevance of the model is also measured by Stone-Geisser's $Q^{2}$, which is the result of the blindfolding procedure. According to Hair et al. [41], the model's predictive relevance is established in the case of positive $Q^{2}$ values. In this study, the value of $\mathrm{Q}^{2}$ for the endogenous construct was almost 0.2 , which showed a medium predictive relevance of the partial least squares model. Both indicators $\left(\mathrm{R}^{2}\right.$ and $\mathrm{Q}^{2}$ ) signaled quite sufficient explanatory power of the proposed model. They implied that factors such as learners' interaction with peers, instructors and contents, and their PIS could affect learners' SR. It is found in this study that learners' SR had the most significant predictive relevance (0.192), while L-L interaction reported the smallest predictive relevance of 0.091 .

The effect size measured by $\mathrm{f}^{2}$ indicates the strength of the influence exogenous constructs have on endogenous constructs by examining changes in the coefficient of determination when an exogenous construct is removed from the model. Data in Table 4 shows that effects from PIS to L-I interaction reported the most considerable value $(0.256)$ while $\mathrm{L}-\mathrm{L}$ interaction to learners' SR obtained the smallest $\mathrm{f}^{2}$ of 0.057 . 
Table 4. Effect size.

\begin{tabular}{lcc}
\hline & f Square & Effect size \\
\hline Internet Self Efficacy -> Learner-Content & 0.199 & Medium \\
Internet Self Efficacy -> Learner-Instructor & 0.256 & Medium \\
Internet Self Efficacy -> Learner-Learner & 0.197 & Medium \\
Internet Self Efficacy -> Learners' Self Regulation & 0.110 & Small \\
Learner-Content -> Learners' Self Regulation & 0.067 & Small \\
Learner-Instructor -> Learners' Self Regulation & 0.100 & Small \\
Learner-Learner -> Learners' Self Regulation & 0.057 & Small \\
\hline
\end{tabular}

Table 5. Indirect effects and significance.

Internet Self Efficacy -> Learner-Content -> Learners' Self Regulation Internet Self Efficacy -> Learner-Instructor -> Learners' Self Regulation Internet Self Efficacy -> Learner-Learner -> Learners' Self Regulation

$\begin{array}{cc}\text { Specific Indirect Effects } & \text { Significance } \\ 0.088 & \mathbf{0 . 0 0 0} \\ 0.126 & \mathbf{0 . 0 0 0} \\ 0.080 & \mathbf{0 . 0 0 0}\end{array}$

Table 6. Multiple group analysis of path coefficients and total effects.

Path Coefficients/Direct Effects

Internet Self Efficacy -> Learner-Content

Internet Self Efficacy -> Learner-Instructor

Internet Self Efficacy -> Learner-Learner

Internet Self Efficacy -> Learners' Self Regulation

Learner-Content -> Learners' Self Regulation

Learner-Instructor -> Learners' Self Regulation

Learner-Learner -> Learners' Self Regulation

Total Effects

Internet Self Efficacy -> Learner-Content

Internet Self Efficacy $->$ Learner-Instructor

Internet Self Efficacy -> Learner-Learner

Internet Self Efficacy -> Learners' Self Regulation

Learner-Content -> Learners' Self Regulation

Learner-Instructor -> Learners' Self Regulation

Learner-Learner -> Learners' Self Regulation

Internet Self Efficacy -> Learner-Content -> Learners' Self Regulation Internet Self Efficacy -> Learner-Instructor -> Learners' Self Regulation Internet Self Efficacy -> Learner-Learner -> Learners' Self Regulation
PLS-MGA Significance (0.05)

Male vs Non-language No Experience vs

Female vs Language Experience

No No No

No Yes No

No Yes No

No No Yes

No Yes No

No No No

No No $\quad$ No

PLS-MGA Significance (0.05)

Male vs Non-language No Experience vs

Female vs Language Experience

No No No

No Yes No

No Yes No

No No Yes

No Yes No

No No No

No No $\quad$ No

PLS-MGA Significance (0.05)

Male vs Non-language No Experience vs

Female vs Language Experience

No No No

No Yes No

No No No 


\subsection{Path Coefficients and Hypotheses Testing Results}

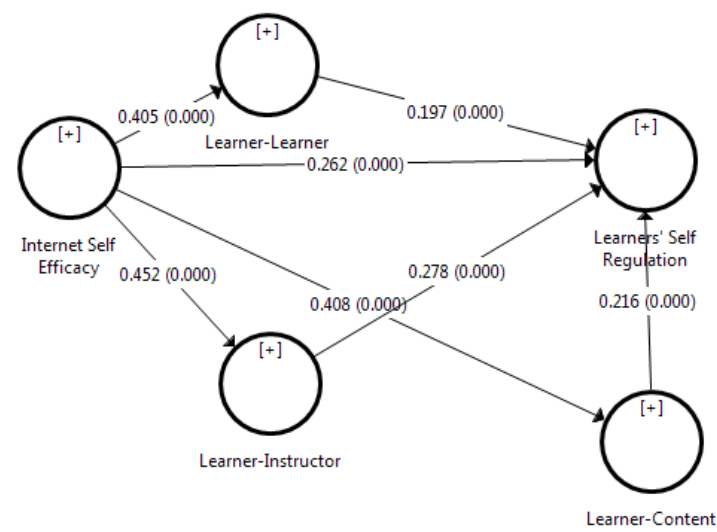

Figure 2. Path coefficients and significance.

The standardized direct and indirect effects of PIS on three types of interaction and SR are presented in Figure 2 and Table 5. The study finds statistical support for construct interrelationships, represented by significant path coefficients and total effects in the model. More specifically, the total effects of all paths were positive at a $5 \%$ level of significance, implying that all relationships in the proposed model explained the degree of student perceptions towards their SR. The effects of PIS were profound for SR (0.556) and quite noticeable for the remaining constructs (just under 0.5). This indicates that PIS was a significant and relevant factor determining how learners interacted in an online environment and thus controlled their SR level. However, the total small effects (around 0.2) of three types of interaction on SR suggested that these were the areas that needed improvements to increase the level of SR of online learners.

\subsection{Multigroup Analysis}

Three multigroup analyses are conducted in this study: male versus female, non-language versus

Table 7. Summary of significant differences.

\begin{tabular}{lcc}
\hline Internet Self Efficacy -> Learne rs ' Self Regulation & No Experience & Experience \\
\hline Path Coefficients/Direct Effects & 0.226 & 0.351 \\
Total Effects & 0.524 & 0.640 \\
\hline Internet Self Efficacy -> Learner-Instructor & Non-language & Language \\
\hline Path Coefficients/Direct Effects & 0.398 & 0.484 \\
\hline Internet Self Efficacy -> Learne r-Learner & Non-language & Language \\
\hline Path Coefficients/Direct Effects & 0.329 & 0.452 \\
\hline Learner-Content -> Learners' Self Regulation & Non-language & Language \\
\hline Path Coefficients/Direct Effects & 0.282 & 0.186
\end{tabular}

language major, and experienced versus inexperienced students. Details can be seen in Table 6 and Table 7.

The multigroup analysis shows that there was no significant difference between male and female groups in all the relationships among the constructs. However, it indicates that non-language and language majors were significantly different in the direct and total effects for paths from PIS to $\mathrm{L}-\mathrm{L}$ and $\mathrm{L}-\mathrm{L}$ interaction and from $\mathrm{L}-\mathrm{C}$ interaction to learners' $\mathrm{SR}$ at a $5 \%$ significance level. More specifically, non-language students perceived $\mathrm{L}-\mathrm{C}$ interaction was more influential to SR than language counterparts $(0.282$ versus 0.186 ). Conversely, language majors placed a higher impact of PIS on L-I and L-L interaction than non-language students $(0.484$ versus 0.398 and 0.452 versus 0.329). Finally, experienced students believed that PIS had more impact on SR than inexperienced students (0.64 versus 0.53$)$.

\section{DISCUSSION}

The current study employed the partial least squares structural equation modeling (PLS-SEM) analysis to explore the predicting power of online interaction and learner Internet self-efficacy on learner self-regulation in a higher education context in Vietnam during online learning amid Covid-19. The assessment of the study's measurement model indicated that the model was valid and reliable. This assessment result accorded similar testing scales in previous studies [45], [46]. By calculating standardized direct and indirect effects, the study findings showed statistical support for interrelationships among the constructs, represented by significant path coefficients and total effects in the model. The results of this study will now be compared to the findings of previous works.

First of all, the current study predicts a positive direct and indirect influence of PIS on SR, which partly agrees with the findings of the study by Hatlevik et al. [23], which demonstrates that learners' ICT selfefficacy and self-regulation are closely related. The predictive power of Internet self-efficacy on self-regulation in this study also supports, in part, the findings of studies by Yilmaz [25] and Tsai and Tsai [24], which respectively showed the indirect effects of Internet selfefficacy on motivated strategies for learning and study gains. 
This study further shows that Internet self-efficacy could be a positive predictor of learners' selfregulation. In other words, learners with higher competencies in using the Internet tend to have better online self-regulation skills. When students are eager to learn something new, they are more proactive in adjusting learning strategies. This finding matches those observed in earlier studies. For example, students optimize learning strategies by continuously assessing their efficacy to meet new learning needs [48]. In addition, the unprecedented online learning context could have triggered their innovation in learning [49].

Nonetheless, the small effect size (measured by $\mathrm{f}^{2}$ ) from Internet self-efficacy to self-regulation in the current study seems to indicate that learners' competencies in using the Internet did not directly have a strong and meaningful effect on self-study. This implies that Internet skills were not sufficiently utilized to enhance self-regulation in emergency online learning contexts directly. The present findings seem to be consistent with other research, which found that the Internet's use had a weak influence on academic achievement [50]. A possible explanation for these results may be the lack of technological preparation from both teachers and students, many of whom had never been online for teaching and learning before [2].

The study's proposed model did not investigate the influence of interaction on satisfaction as in those in the literature. On the other hand, it predicted the effects of learners' Internet self-efficacy on three types of interaction and self-regulation. The small effect of the three types of interaction on self-regulation may imply that both teachers and students need more support in fostering class interaction [2]. To our knowledge, this is the first study that used PLS-SEM to predict the combined effects of Internet selfefficacy and three types of interaction on learner selfregulation, especially during the live online learning during the Covid-19 pandemic. The investigation on the combined effects of a number of constructs on learner self-regulation in the current study acts on the suggestion put forward by Kuo et al. [9, p. 46], "Future studies attempting to predict student satisfaction are encouraged to take into account potential clustering effects."

This study detected no differences between female and male students in the relationship between the constructs: Internet self-efficacy, interaction, and selfregulation. These results are, in part, in agreement with the findings of Maheshwari et al. [2] and Wang et al. [51], which found no gender differences in the correlational path between different constructs of mobile learning intention. However, few research projects have explored gender differences in the relational paths among different model variables. Hence, the above results need to be interpreted with caution.

Likewise, few studies in the literature have explored the impact of prior online learning experience and study majors on the relationships between different constructs of online learning. Past studies tended to look at the differences of experience and study major on a single construct, such as Internet self-efficacy and Internet anxiety or Internet selfefficacy on motivation and satisfaction [52], [53]. The current study predicted differences in Internet selfefficacy and study major in the relational paths from Internet self-efficacy to learner self-regulation. As a comparison, our findings are, in part, in agreement with Mekhzoumi et al. [54], which revealed some differences between English and non-English majors in the correlational path between different constructs of mobile learning intention. However, with a limited number of similar studies, the above results should be interpreted cautiously.

\section{CONCLUSIONS, LIMITATIONS AND IMPLICATIONS}

The Covid-19 pandemic posed enormous challenges for Vietnamese education; yet, it offered great opportunities for online teaching and learning [2]. There have been studies on different factors that play important roles in this learning mode in Vietnam, including live online interaction, Internet efficacy and learners' self-study skills. This study shows that learner Internet self-efficacy was one of the most critical factors influencing their online interaction and self-regulation in live online lessons. However, the influence of three types of interaction on selfregulation was small. In the live online learning context, learners' competencies in using the Internet seem to be effective in fostering interaction and selfregulation, which is significantly influential to learner satisfaction [9], [3]. Being considered digital natives, learners' capability to use computers and the Internet for learning is no longer an obstacle [30]. Nonetheless, in a developing country like Vietnam, attention should be paid to this matter due to the weak digital competence of many students [2], [5].

The continuous outbreaks of Covid-19 worldwide and in Vietnam call for the need to prepare for longterm online teaching and learning. The recent MOET circular about online teaching at the school level [7] focuses mainly on the teaching side. While this might 
be the right direction at the school level, more attention should be paid to developing self-study or selfregulation strategies at the higher education level. In this regard, learners' online self-regulation is one of the key aspects that universities should consider in their investment in infrastructure and human resources for online teaching and learning. In other words, university managers and teachers should focus on developing online course content and teaching competencies, and at the same time, providing students with instructions on how to study independently. This is in line with the innovative learning environment approach in which selfregulated inquiry plays a central role in enhancing students' learning performance [49].

One of the limitations of this study was that the quantitative data were collected via self-reporting, which could have been subject to biases. This is especially true when only one-fourth of the participants had had some experience in online learning before. In future studies, data should be gathered from other sources, especially from learners' actual use of specific video conferencing applications like Zoom or Google Meet to increase data validity and reliability. Second, this study has only concentrated on the undergraduates whose Internet competencies, online interaction skills, and self-study strategies can be different from school students. Hence, future research projects should be conducted with both high school and university students to see if there are any differences in the factors mentioned above. Third, the study did not survey the instructors who should play the role of content designers, interaction promoters, and self-regulation guides. Therefore, future research should explore instructors' perceptions about their experience of working with the students in online live lessons. Finally, the sample was collected only in Vietnam, and there is a limitation over the transferability of the findings in other Asian contexts. Thus, future studies should be expanded to other countries with different contexts to Vietnam to understand the relationship between Internet competencies, online interaction patterns and selfregulation in the live online lessons.

\section{REFERENCES}

[1] G. Huy, "Xác định dạy học trực tuyến là giải pháp lâu dài [Online learning as a long term solution]," 2021. [Online]. Available: https://thanglong.chinhphu.vn/xac-dinh-day-hoc-tructuyen-la-giai-phap-lau-dai

[2] G. Maheshwari, "Factors affecting students' intentions to undertake online learning: An empirical study in Vietnam," Education and Information Technologies, vol. 2021, pp. 1-21, 2021, doi: 10.1007/s10639-021-10465-8.

[3] P. Thach, P. Lai, V. Nguyen, and H. Nguyen, "Online learning amid Covid-19 pandemic: students' experience and satisfaction," Journal of e-Learning and Knowledge Society, vol. 17, no. 1, pp. 39-48, Jun. 2021, doi: 10.20368/1971-8829/1135293.

[4] H. Baber, "Determinants of students' perceived learning outcome and satisfaction in online learning during the pandemic of Covid-19," Journal of Education and e-Learning Research, vol. 7, no. 3, pp. 285-292, 2020 , doi: 10.20448/journal.509.2020.73.285.292.

[5] T. Tran et al., "How digital natives learn and thrive in the digital age: Evidence from an emerging economy," Sustainability, vol. 12, no. 9, pp. 1-24, May. 2020, doi: 10.3390/su12093819.

[6] MOETb, "The information and communications going along with education and training in the preventing Covid-19.," 2020. https://en.moet.gov.vn/news/Pages/events.aspx?ItemI $\mathrm{D}=3933$

[7] MOETc, "Circular about organization and management of online teaching in schools and continuing education institutions." 2021. [Online]. Available: https://moet.gov.vn/vanban/vanban/Pages/chi-tiet-vanban.aspx?ItemID=1396

[8] MOETa, "Đại học tiên phong đẩy mạnh chuyển đổi số giáo dục [Universities pioneer in educational digitalization]," 2020. https://moet.gov.vn/tintuc/Pages/phong-chongnCoV.aspx?ItemID $=6615$

[9] Y.-C. Kuo, A. E. Walker, K. E. E. Schroder, and B. R. Belland, "Interaction, Internet self-efficacy, and self-regulated learning as predictors of student satisfaction in online education courses," The Internet and Higher Education, vol. 20, no. 2014, pp. 35-50, 2014, doi: 10.1016/j.iheduc.2013.10.001.

[10] J. Wong, M. Baars, D. Davis, T. Van Der Zee, G.J. Houben, and F. Paas, "Supporting self-regulated learning in online learning environments and MOOCs: A systematic review," International Journal of Human-Computer Interaction, vol. 35, no. 4-5, pp. 356-373, Mar. 2019, doi: $\underline{10.1080 / 10447318.2018 .1543084 .}$

[11] T. N. Nguyen, D. Tangen, and D. Beutel, "Exploring the concept of learner autonomy in cross- 
cultural research," SiSAL Journal: Studies in SelfAccess Learning, vol. 5, no. 3, Art. No. 3, 2014.

[12] D. S. Nagar, "Assessing students' perception toward e-learning and effectiveness of online sessions amid Covid-19 lockdown phase in India: An analysis," UGC Care Journal, vol. 19, no. 13, pp. 272-291, 2020.

[13] G. Murray, "The social dimensions of learner autonomy and self-regulated learning," Studies in SelfAccess Learning Journal, vol. 5, no. 4, pp. 320-341, 2014.

[14] B. J. Zimmerman, "A social cognitive view of self-regulated academic learning.," Journal of Educational Psychology, vol. 81, no. 3, pp. 329-339, 1989, doi: https://psycnet.apa.org/doi/10.1037/00220663.81.3.329.

[15] D. H. Schunk and B. J. Zimmerman, "Social origins of self-regulatory competence," Educational Psychologist, vol. 32, no. 4, pp. 195-208, Sep. 1997, doi: 10.1207/s15326985ep3204_1.

[16] M.-H. Cho and Y. Cho, "Self-regulation in three types of online interaction: A scale development," Distance Education, vol. 38, no. 1, pp. 70-83, Jan. 2017, doi: 10.1080/01587919.2017.1299563.

[17] K. M. Hamdan, A. M. Al-Bashaireh, Z. Zahran, A. Al-Daghestani, S. AL-Habashneh, and A. M. Shaheen, "University students' interaction, Internet self-efficacy, self-regulation and satisfaction with online education during pandemic crises of COVID19 (SARS-CoV-2)," International Journal of Educational Management, vol. 35, no. 3, pp. 713-725, Jan. 2021, doi: 10.1108/IJEM-11-2020-0513.

[18] B. Landrum, "Examining students' confidence to learn online, self-regulation skills and perceptions of satisfaction and usefulness of online classes," Online Learning, vol. 24, no. 3, pp. 128-146, Sep. 2020, doi: https://doi.org/10.24059/olj.v24i3.2066.

[19] S. Eom and N. Ashill, "The determinants of students' perceived learning outcomes and satisfaction in university online education: An update," Decision Sciences Journal of Innovative Education, vol. 14, no. 2, pp. 185-215, Apr. 2016.

[20] A. Bandura, "Self-efficacy: Toward a unifying theory of behavioral change," Psychological Review, vol. 84, no. 2, pp. 191-215, 1977, doi: $10.1037 / 0033-$ 295X.84.2.191.

[21] D. H. Schunk, "Self-efficacy and achievement behaviors," Educational Psychology Review, vol. 1, no. 3, pp. 173-208, Sep. 1989, doi: 10.1007/BF01320134.

[22] A. Rohatgi, R. Scherer, and O. E. Hatlevik, "The role of ICT self-efficacy for students' ICT use and their achievement in a computer and information literacy test," Computers \& Education, vol. 102, pp. 103-116, Nov. 2016, doi: 10.1016/j.compedu.2016.08.001.

[23] O. E. Hatlevik, I. Throndsen, M. Loi, and G. B. Gudmundsdottir, "Students' ICT self-efficacy and computer and information literacy: Determinants and relationships," Computers \& Education, vol. 118, pp. 107-119, 2018, doi: https://doi.org/10.1016/j.compedu.2017.11.011.

[24] M.-J. Tsai and C.-C. Tsai, "Information searching strategies in web-based science learning: The role of Internet self-efficacy," Innovations in Education and Teaching International, vol. 40, pp. 43-50, Feb. 2003, doi: $10.1080 / 1355800032000038822$.

[25] R. Yilmaz, "Exploring the role of e-learning readiness on student satisfaction and motivation in the flipped classroom," Computers in Human Behavior, vol. 70, pp. 251-260, 2017, doi: 10.1016/j.chb.2016.12.085.

[26] E. Alqurashi, "Predicting student satisfaction and perceived learning within online learning environments," Distance Education, vol. 40, no. 1, pp. 133-148, 2019, doi: 10.1080/01587919.2018.1553562.

[27] M. G. Moore, "Editorial: Three types of interaction," American Journal of Distance Education, vol. 3, no. 2, pp. 1-7, Jan. 1989, doi: $10.1080 / 08923648909526659$.

[28] D. C. A. Hillman, D. J. Willis, and C. N. Gunawardena, "Learner-interface interaction in distance education: An extension of contemporary models and strategies for practitioners," American Journal of Distance Education, vol. 8, no. 2, pp. 3042, Jan. 1994, doi: 10.1080/08923649409526853.

[29] A. N. Ganayem and W. S Zidan, "21st century skills: Student perception of online instructor role," Interdisciplinary Journal of e-Skills and Lifelong Learning (IJELL), vol. 14, pp. 117-141, 2018, doi: $10.28945 / 4090$.

[30] Y. M. Tang et al., "Comparative analysis of student's live online learning readiness during the coronavirus (COVID-19) pandemic in the higher education sector," Computers \& Education, vol. 168, 
p. 104211, Jul. 2021, doi: 10.1016/j.compedu.2021.104211.

[31] M. Adnan and K. Anwar, "Online learning amid the covid-19 pandemic: Students' perspectives," Journal of Pedagogical Sociology and Psychology, vol. 2, no. 1, pp. 45-51, 2020, doi: http://www.doi.org/10.33902/JPSP.

[32] C. Y. R. Loh and T. C. Teo, "Understanding Asian students learning styles, cultural influence and learning strategies," Journal of Education \& Social Policy, vol. 7, no. 1, pp. 194-210, 2017.

[33] H. Ghadirian, A. Fauzi Mohd Ayub, and K. Salehi, "Students' perceptions of online discussions, participation and e-moderation behaviors in peermoderated asynchronous online discussions," Technology, Pedagogy and Education, vol. 27, no. 1, pp. 85-100, Jan. 2018, doi: 10.1080/1475939X.2017.1380695.

[34] W. S. Chen and A. Y. Tat Yao, "An empirical evaluation of critical factors influencing learner satisfaction in blended learning: A pilot study," Universal Journal of Educational Research, vol. 4, no. 7, pp. 1667-1671, 2016, doi: 10.13189/ujer.2016.040719.

[35] B. G. Gameel, "Learner satisfaction with massive open online courses," American Journal of Distance Education, vol. 31, no. 2, pp. 98-111, Apr. 2017, doi: 10.1080/08923647.2017.1300462.

[36] J. W. Lee, P. S. Jones, Y. Mineyama, and X. E. Zhang, "Cultural differences in responses to a Likert scale," Research in Nursing and Health, vol. 25, no. 4, pp. 295-306, Aug. 2002, doi: 10.1002/nur.10041.

[37] R. Wang, B. Hempton, J. P. Dugan, and S. R. Komives, "Cultural differences: Why do Asians avoid extreme responses?," Survey Practice, vol. 1, no. 3, 2008, doi: https://doi.org/10.29115/SP-2008-0011.

[38] M. S. Eastin and R. LaRose, "Internet selfefficacy and the psychology of the digital divide," Journal of Computer-Mediated Communication, vol. 6, no. 1, Sep. 2000, doi: 10.1111/j.10836101.2000.tb00110.x.

[39] R. S. Jansen, A. van Leeuwen, J. Janssen, L. Kester, and M. Kalz, "Validation of the self-regulated online learning questionnaire," Journal of Computing in Higher Education, vol. 29, no. 1, pp. 6-27, Apr. 2017, doi: 10.1007/s12528-016-9125-X.

[40] H. Wold, "Path models with latent variables: The NIPALS approach," in Quantitative Sociology,
Academic Press, 1975, pp. 307-357. doi: 10.1016/B978-0-12-103950-9.50017-4.

[41] J. F. Hair, M. C. Howard, and C. Nitzl, “Assessing measurement model quality in PLS-SEM using confirmatory composite analysis," Journal of Business Research, vol. 109, pp. 101-110, Mar. 2020, doi: 10.1016/j.jbusres.2019.11.069.

[42] E. E. Rigdon, "Rethinking partial least squares path modeling: In praise of simple methods," Long Range Planning, vol. 45, no. 5-6, pp. 341-358, Oct. 2012, doi: 10.1016/j.lrp.2012.09.010.

[43] J. Henseler, C. M. Ringle, and M. Sarstedt, "A new criterion for assessing discriminant validity in variance-based structural equation modeling," Journal of the Academy of Marketing Science, vol. 43, no. 1, pp. 115-135, Jan. 2015, doi: 10.1007/s11747-0140403-8.

[44] C. M. Ringle, S. Wende, and J.-M. Becker, SmartPLS 3.3.2, SmartPLS. Bonningstedt: SmartPLS, 2015. [Online]. Available: http://www.smartpls.com

[45] A. J. Barrett, A. Pack, and E. D. Quaid, "Understanding learners' acceptance of highimmersion virtual reality systems: Insights from confirmatory and exploratory PLS-SEM analyses," Computers \& Education, vol. 169, no. 2021, pp. 1-17, Aug. 2021, doi: 10.1016/j.compedu.2021.104214.

[46] S. Sukendro et al., "Using an extended technology acceptance model to understand students' use of e-learning during Covid-19: Indonesian sport science education context," Heliyon, vol. 6, no. 11, Nov. 2020, doi: 10.1016/j.heliyon.2020.e05410.

[47] C. Mircioiu and J. Atkinson, "A comparison of parametric and non-parametric methods applied to a Likert scale," Pharmacy, vol. 5, no. 2, Art. no. 2, 2017, doi: $10.3390 /$ pharmacy 5020026 .

[48] E. Cheng, "The role of self-regulated learning in enhancing learning performance," The International Journal of Research and Review, vol. 6, no. 1, pp. 116, Jan. 2011.

[49] M. Huda, Z. Haron, M. N. Ripin, A. Hehsan, and A. B. C. Yaacob, "exploring innovative learning environment (ILE): Big data era," International Journal of Applied Engineering Research, vol. 12, no. 17, pp. 6678-6685, 2017.

[50] M. S. Shahibi and Rusli, "The influence of internet usage on student's academic performance," International Journal of Academic Research in Business and Social Sciences, vol. 7, no. 8, pp. 873- 
887, Sep. 2017, doi: http://dx.doi.org/10.6007/IJARBSS/v7-i8/3301.

[51] Y.-S. Wang, M.-C. Wu, and H.-Y. Wang, "Investigating the determinants and age and gender differences in the acceptance of mobile learning," British Journal of Educational Technology, vol. 40, no. 1, pp. 92-118, 2009, doi: 10.1111/j.14678535.2007.00809.x.

[52] C.-S. Chang, E. Z.-F. Liu, H.-Y. Sung, C.-H. Lin, N.-S. Chen, and S.-S. Cheng, "Effects of online college student's Internet self-efficacy on learning motivation and performance," Innovations in Education and Teaching International, vol. 51, no. 4, pp. 366-377, Jul. 2014, doi: $\underline{10.1080 / 14703297.2013 .771429 .}$.

[53] N. Paul and M. Glassman, "Relationship between Internet self-efficacy and Internet anxiety: A Nuanced approach to understanding the connection," AJET, vol. 33, no. 4, pp. 147-165, Apr. 2017, doi: 10.14742/ajet.2791.

[54] O. Mekhzoumi, M. H. bin Hamzah, and H. N. Krishnasamy, "Determinants of mobile applications acceptance for English language learning in Universiti Utara Malaysia," Journal of Advanced Research Design, vol. 51, no. 1, pp. 1-13, 2018. 